\title{
Aromatherapy with ylang ylang for anxiety and self-esteem: a pilot study
}

\author{
AROMATERAPIA COM YLANG YLANG PARA ANSIEDADE E AUTOESTIMA: ESTUDO PILOTO
}

AROMATERAPIA CON YLANG-YLANG PARA LAANSIEDAD Y AUTOESTIMA: UN ESTUDIO PILOTO

\author{
Juliana Rizzo Gnatta1, Patricia Petrone Piason², Cristiane de Lion Botero Couto Lopes ${ }^{3}$, Noemi \\ Marisa Brunet Rogenski ${ }^{4}$, Maria Júlia Paes da Silva
}

\begin{abstract}
Objective: To verify if the use of ylang ylang essential oil by cutaneous application or inhalation alters the anxiety and self-esteem perception and physiological parameters as blood pressure and temperature. Method: A pilot study with 34 professionals from a nursing group randomized in three groups: one received the ylang ylang essential oil by cutaneous application, the second received through inhalation and the third (placebo) received the ylang ylang essence through cutaneous application. The assessment was done by an Anxiety Inventory (IDATE) and the Dela Coleta self-esteem scale, applied on baseline, after 30, 60 and 90 days and after 15 days post-intervention (follow up). Results: In the pre and post-intervention intergroup analysis, there was a significant difference in self-esteem for the three groups ( $p$ values: $G 1=0.014 ; G 2=0.016$; $\mathrm{G} 3=0.038$ ). There were no differences in the analysis between groups for anxiety or for physiological parameters. Conclusion: It was found significant alterations only to the intergroup perception of self-esteem for the three groups.
\end{abstract}

\section{DESCRIPTORS}

Aromatherapy

Cananga

Anxiety

Self concept

Complementary therapies

Nursing

\section{RESUMO}

Objetivo: Verificar se o uso do óleo essencial de ylang ylang por meio de aplicação cutânea ou inalatória altera a percepção da ansiedade e da autoestima e os parâmetros fisiológicos como pressão arterial e temperatura. Método: Estudo piloto no qual participaram 34 profissionais da equipe de enfermagem randomizados em três grupos: um recebeu o óleo essencial de ylang ylang via cutânea, o segundo o recebeu via inalatória e o terceiro (placebo) recebeu essência de ylang ylang via cutânea. A avaliação foi feita por meio do Inventário de Ansiedade (IDATE) e da escala de autoestima de Dela Coleta que foram aplicadas antes, ao final de 30, 60 e 90 dias e 15 dias (follow up) após o término do uso. Resultados: Na avaliação intragrupo, antes e após a intervenção, houve diferença significante para os três grupos na variável autoestima (valores de p: G1=0,014; $\mathrm{G} 2=0,016 ; \mathrm{G} 3=0,038$ ). Não houve diferenças nas análises entre grupos para a ansiedade ou para os parâmetros fisiológicos. Conclusão: Houve alterações significativas apenas na percepção da ansiedade intragrupo para os três grupos.

DESCRITORES
Aromaterapia
Cananga
Ansiedade
Autoimagem
Terapias complementares;
Enfermagem

\section{RESUMEN}

Objetivo: Verificar si el uso del aceite esencial de ylang ylang por medio de la aplicación cutánea o la inhalación altera la percepción de la ansiedad y autoestima, así como de los parámetros fisiológicos de presión arterial y temperatura corporal. Método: Estudio piloto en el cual participaron 34 profesionales de enfermería distribuidos en tres grupos: el primero recibió aceite esencial por vía tópica, el segundo por vía inhalatoria y el tercero (placebo) esencia de ylang ylang por vía tópica. La evaluación se realizó aplicando el Inventario de Ansiedad (IDATE) y la Escala de Autoestima de Dela Coleta antes y después de 30, 60 y 90 días y 15 días después del período de uso. Resultados: En la evaluación intra grupo, antes y después de la intervención, hubo diferencias significativas para los tres grupos en la variable autoestima (valores p: $\mathrm{G} 1=0,014 ; \mathrm{G} 2=0,016$; $\mathrm{G} 3=0,038)$. No hubo diferencias en los análisis entre grupos para la ansiedad o para los parámetros fisiológicos. Conclusión: Hubo solamente cambios significativos en la percepción de la autoestima intra grupo para los tres grupos.

DESCRIPTORES
Aromaterapia
Cananga
Ansiedad
Autoimagen
Terapias complementarias
Enfermería

${ }^{1}$ PhD student in Health Sciences, Nursing School, Universidade de São Paulo, São Paulo, SP, Brazil. juliana.gnatta@gmail.com 2 Bachelor student in Nursing, Nursing School, Universidade de São Paulo, São Paulo, SP, Brazil. ${ }^{3}$ Chief Nurse in the Central of Materials and Sterilization, Hospital Universitário, Universidade de São Paulo, São Paulo, SP, Brazil. ${ }^{4}$ Director of Surgical Nursing Division, Hospital Universitário, Universidade de São Paulo, São Paulo, SP, Brazil. ${ }^{5}$ Head Professor, Department of Medical-Surgical Nursing, Nursing School, Universidade de São Paulo, São Paulo, SP, Brazil.

$\begin{aligned} \text { Rev Esc Enferm USP } & \text { Received: } 11 / 22 / 2013 \\ \text { 2014; 48(3):492-9 } & \text { Approved: 03/27/2014 }\end{aligned}$




\section{INTRODUCTION}

Aromatherapy is a therapeutic technique based in the use of essential oils (EO). Aroma means pleasant odor and therapy means treatment that aims cure of a physical, emotional or mental indisposition. This practice uses volatile concentrates extracted from plants - essential oils and its objective is to modify a behavior or humor. The EO is a condensate obtained from vegetable distillated materials, as roots, stems, leaves, flowers, fruits, seeds and resins $^{(1)}$. They are composed by high complexity chemical molecules that can be applied directly to the skin or to be inhaled. When the contact is cutaneous, the EO crosses the skin barrier due to its small and low weight molecules, they are absorbed and falls into the blood stream which transports it to the tissues and organs ${ }^{(2)}$. When the OE is inhaled, its molecules are absorbed by the nostrils and it contacts the olfactory nerves that are directly connected to the Central Nervous System and take the stimulus to the Limbic System that is responsible for the feelings, memory, impulses and emotions ${ }^{(2)}$.

The aromatherapy can be used with massage and it is absorbed by the skin or olfactory system. Studies found that the olfactory stimulus produces changes in parameters as blood pressure and in skin temperature ${ }^{(3)}$, it reduces anxiety by massage and aromatherapy in breast cancer patients ${ }^{(4)}$, reduces anxiety in nurses of emergency team during the winter and summer with massage and aromatherapy ${ }^{(5)}$ and has positive effects in anxiety and self-esteem in elderly woman through massage, aromatherapy and music ${ }^{(6)}$.

A research was conducted recently in a teaching hospital about the use of aromatherapy with ylang ylang and rose EO to enhance self-esteem in workers from the Central of Material and Sterilization and Hygiene Service ${ }^{(7)}$. The results pointed that more studies are needed with an initial sample with low self-esteem and that investigates the best way to deliver the EO (cutaneous or inhalation), as well as its frequency of use. Proposals like this, which cares for nursing professionals, has represented a new path to quality assistance. The excellence in the Nursing care also depends on the professional's psycho emotional condition, therefore the focus of caring for the team member helps to build a healthier work environment and to perform a more structured, planned and solid care ${ }^{(8)}$.

Thus, a tool, which can be implemented to the Nursing care, is the aromatherapy, considered one of the Natural Therapies/Traditional and Complementary/Not Conventional in accordance with the Municipal Law of São Paulo 13.717, implemented in $2004^{(9)}$. The World Health Organization ${ }^{(10)}$ has stimulated the use of Complementary Therapies (CT) and the development of scientific studies to obtain better knowledge of efficacy, safety and quality of those practices. In the case of Nursing, the use of CT can be promoted by its professionals once the specific law from the regulatory sector of their profession to practice it ${ }^{(11)}$ protects them.
The ylang ylang (Cananga odorata) EO was chosen for this research due to its aroma's therapeutic properties as described in the literature. It is found that the ylang ylang oil is antidepressant and it is indicated for anxiety, frustrations, nervous tension, fear and depression ${ }^{(1-2,12)}$, and it was used for a self-esteem study with a Nursing team ${ }^{(7)}$. Low self-esteem and anxiety can be related to many or few of those emotional conditions. This OE is chemically derived from the mevalonic acid, which comes from the Acetyl coenzyme A. Hydrocarbons and hydroxyl groups constitute it, which gives it a pleasant odor and generates a revitalizing sensation ${ }^{(12)}$.

Anxiety is an emotional state that encloses psychological and physiological components and it has feelings as fear, insecurity, apprehension and alert state alteration. Anxiety becomes pathologic when it is not proportional to the situation which started it, or when there is no specific object directed $^{(13)}$.

Self-esteem incorporates two components: sense of personal competence and sense of personal value. If those two are unbalanced, there is negative self-esteem, which manifests inadequacy, insecurity, doubts, guilt and fear. When balanced, the positive self-esteem generates confidence towards life, competence and merit feelings. Self-esteem does not show as negative or positive, but when in low levels, every human being is capable of developing and enhancing $\mathrm{it}^{(14)}$.

The present study used aromatherapy with ylang ylang EO as care tool for the nursing group, questioning if this practice produces positive effects for anxiety and low self-esteem enhancement for nursing professionals. The study objectives were to verify if the ylang ylang EO alters anxiety and self-esteem perception, to compare if the application of ylang ylang EO by cutaneous or inhaling paths alters the physiological parameters measured through mean blood pressure and temperature.

\section{METHOD}

An experimental controlled field pilot study with quantitative approach, conducted at the University Hospital from Universidade de São Paulo (HU-USP). The study attended the Resolution 196/1996, from the National Health Council, involving human beings in the research and it was initiated after the Hospital Research and Ethics Committee approval, under $n^{\circ} 1153 / 11$ SISNEP CAAE 0038.0.198.000-11. Besides that, for ethical matters, it was assured to the participants from the control group the opportunity to use the gel or freshener with the ylang ylang EO after the intervention, for the same period as the study lasted, as a free choice.

Sample inclusion criteria: to be a nursing employee at the HU-USP and not during experience period; to accept participation in the research, to fill and sign the Free 
Informed Consent Term (TCLE); to accept the gel or freshener use with the EO or ylang ylang essence; to answer the Anxiety Inventory ${ }^{(15)}$ (IDATE), the Dela Coleta self-esteem scale $^{(16)}$ and the information about socio demographic data; to present moderate, high or really high anxiety at IDATE ${ }^{(15)}$, medium or low self-esteem at the Dela Coleta scale ${ }^{(16)}$; to accept not wearing perfume during the study period; to accept olfactively the ylang ylang aroma. Sample exclusion criteria: to take vacations or any kind of time out that would affect the oil or essence use during this period, to not adhere to the protocol during baseline testing or, hypotension self-reported.

After the research approval, there was a two-week advertisement by intranet, posters inside elevators, in the unit kitchens and in the HU-USP employees' community center. Those who accepted to participate after learning about the study objective and method, signed the TCLE and after, each volunteer answered the IDATE ${ }^{(15)}$ and the Dela Coleta self-esteem scale ${ }^{(16)}$. As explicated, the subjects with high or really high scores in the IDATE ${ }^{(15)}$ and medium or low self-esteem by the Dela Coleta scale ${ }^{(16)}$ were selected. It was opted to blind the Dela Coleta scale ${ }^{(16)}$ by hiding the word self-esteem in the instrument, as there is a possibility that people have a hard time to assume having a low self-esteem.

Two tests were conducted after the potential subjects were selected and before the randomization. The first one was to verify the EO olfactory acceptance by the possible subject. For that, the ylang ylang EO was offered in a bottle. The person would inhale it and tell if that odor was pleasant. The second test had the intention to maximize the follow-up and the protocol adherence. During one-week period, all participants that were candidates to participate in the study used a gel (carbogel) with only the ylang ylang essence (placebo) with a $2 \%$ concentration. The participants were instructed to use the gel three times a day as follows: when living their homes to go to work at the Institution where the research was conducted, when leaving their shifts and before sleeping. The choice of moments for its application was due to the lack of literature consensus for dose, frequency and ways to apply the oil essences. The indicated points were the two wrists and the sternum area. The gel was applied and massaged in place with circular movements for 30 seconds, until its absorption in each region. After this period, only those who adhered to the gel-placebo as indicated were randomized. In the data collection, it was not informed to them that they were using the placebo product.

The subjects that passed in the two entrance tests were part of the study sample and each one of them were sorted to participate in one of the three groups: Group 1: received the gel with $2 \%$ ylang ylang EO (G1); Group 2: placebo received gel with $2 \%$ ylang ylang essence (G2); Group 3: received a personal freshener with pure ylang ylang EO (G3). It was determined that the placebo group would use the enriched gel with ylang ylang essence for two reasons. First, in accordance with the literature, the EO is composed by a number of chemical substances proper from the plant, which give it the aroma therapeutic property and, for this reason, could not be substituted by a synthetic substance. While the synthetic products, known as essences, acts in only one way (relative to the active chemical compound), the EO acts in a broader way in the body ${ }^{(17)}$. The second reason for opting for only one type of intervention, the essence enriched gel and not the freshener with essence, was because it was considered harder to a subject to adhere to an intervention protocol that demands more time and it is done by himself/herself.

The Group 1 and Group 2 subjects respectively received, one bottle of aromatic gel (carbogel) enriched with $2 \%$ concentration of ylang ylang EO or essence, in accordance to its group. Because it was found studies in the literature that indicated massage with 20 minutes of mean time with EO, three times per week ${ }^{(3,6)}$, it was determined that the gel contact with the skin would also be of 30 minutes/week, Thus, it was oriented that each participant should use the product as described in the start test, during the 90 days.

The Group 3 subjects were responsible for putting one drop of ylang ylang EO on the cotton inside the personal freshener before their work shifts, and it should be used during the whole shift, during a 90 days period. The gel and fresheners were under subjects' responsibility and the researchers gave them.

The data was collected in five moments by the IDATE ${ }^{(15)}$ and the Dela Coleta scale(16), both internationally recognized and validated in Brazil and used in studies that assessed the aroma therapy effect for anxiety ${ }^{(18-19)}$ and self-esteem ${ }^{(7)}$, respectively. The inventory and scale were applied before the start of intervention, after one month using the gel enriched with ylang ylang EO or the personal freshener, after sixty days and after ninety days of use. The data from the fifth moment were obtained at a 15 day after intervention follow-up. Blood pressure and temperature were verified in the five moments.

The data was typed into a Microsoft Excel spreadsheet and processed in the SPSS (Statistical Package for the Social Sciences) version 18.0 and analyzed quantitatively. Before and after tests were conducted for the difference of means for each month of EO use. The study was a before and after design and the subject was its own control. To guarantee reliability in the obtained data, the Cronbach Alpha $(\alpha)$ was applied to the results of IDATE profile and the initial state obtained by those instruments at the first assessment. To assess the self-esteem, anxiety, mean blood pressure and body temperature variables, a paired T-test intragroup before and after the intervention and a Variance Analysis (ANOVA) within groups. It was used the Kolmogorov-Smirnov to verify the data normality and the Levene test for the variances homogeneity.
Aromatherapy with ylang ylang for anxiety and self-esteem: a pilot study Gnatta JR, Piason PP, Lopes CLBC, Rogenski NMB, Silva MJP 


\section{RESULTS}

One hundred and twenty-one nursing professional volunteered to fill the instruments ${ }^{(15-16)}$ to check if they met the indicated points for inclusion. From those, 46 volunteers met the recommended points and did the two initial tests. After one week using the carbogel plus ylang ylang essence, 45 participants started the study and they were randomized in three groups, including 15 in $\mathrm{G} 1,15$ in $\mathrm{G} 2$ and 15 in G3. Before finishing the first month of intervention, there were 11 dropouts because the participants did not adhere to the aroma use during the study as proposed by the protocol. Therefore, stayed in the groups: $\mathrm{G} 1-10 ; \mathrm{G} 2-11 ; \mathrm{G} 3-13$ volunteers. Thirty four subjects finished the study.

The average age for the groups were 43.8 years (median $=45$; standard deviation $=8.46$ ). Thirty-three participants were female and only one male participant in the G1. Three participants from G1 and two from G2 and G3 were using anti-depressant medication. Two subjects from $\mathrm{G} 1$ and two from $\mathrm{G} 3$ were using anti-hypertensive medication.

As mentioned, the two instruments anxiety and selfesteem data collection, the IDATE and the Dela Coleta, were applied in five moments: 1 ) before start using ylang ylang EO or essence (accordingly to the group where the subject were), 2) after 30 days using the aroma, 3) after 60 days, 4) after 90 days and 5) at a 15 day follow-up after using the aroma.

A paired T-test was made for an intergroup analysis comparing the subjects before and after the intervention, therefore, using the moments 1 and 4 . The results are described in Table 1. There were significant differences observed only for the self-esteem variable for the three groups, measured by the Dela Coleta instrument.

Table 1 - Distribution of means and $\mathrm{p}$ values after the paired T-test for intragroup analysis, before and after intervention, for the selfesteem variables (Dela Coleta), Anxiety (Idate State), temperature and blood pressure - São Paulo, 2014

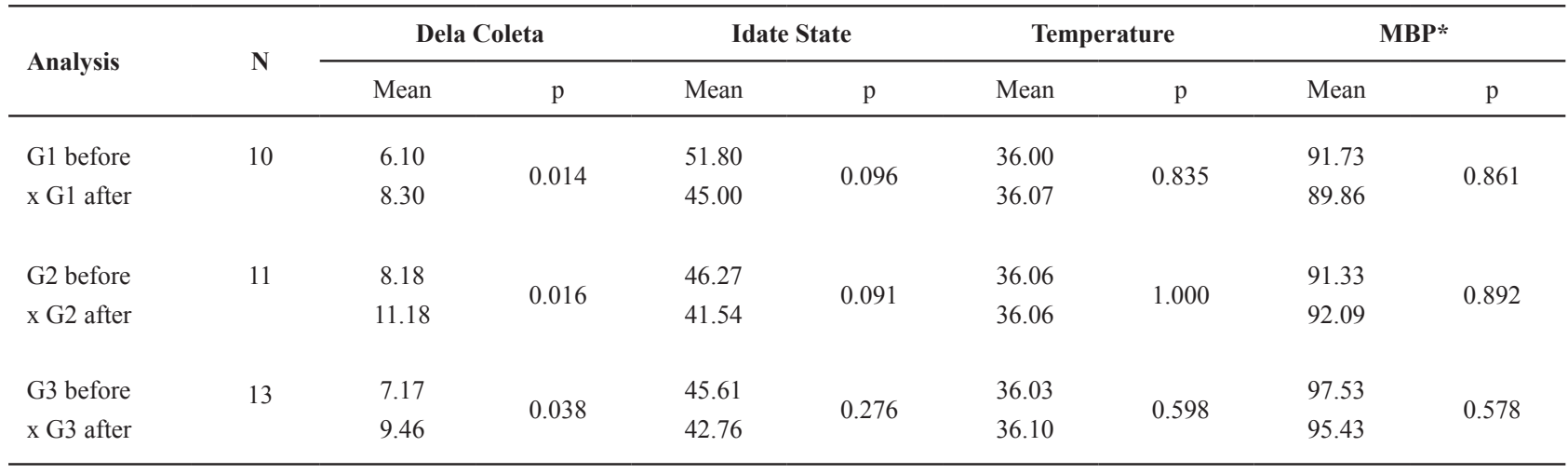

${ }^{*} \mathrm{MBP}=$ mean blood pressure

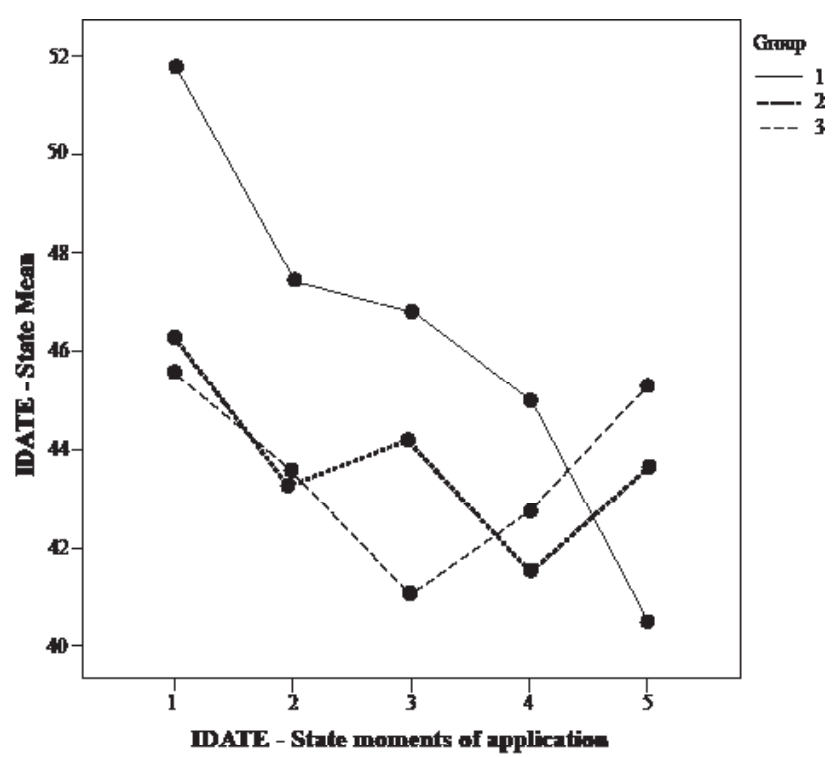

Figure 1 - Distribution of mean score for subject's anxiety according to groups at the five moments of the IDATE-state instrument application - São Paulo, 2014.
To assure the reliability of the collected data for the IDATE instrument ${ }^{(15)}$, it was applied the Cronbach Alpha $(\alpha)$. At the first data collection moment for the IDADEtrace and initial state, it was found 0.808 for the IDADEtrace and 0.931 for the IDATE-initial state.

An ANOVA was performed for the between groups analysis for obtained scores in each moment, as described previously. The sphericity assumption was met (Mauchys test, $p=0.331$ ) and there was no difference between the three groups for the variable anxiety $(p=0.109)$. The Figure 1 demonstrates the scores mean distribution in the five moments of assessment for anxiety, by the IDATEstate instrument. It is observed that the gel plus ylang ylang EO group (G1) shows a tendency to reduce the anxiety scores, kept even after the end of the aroma use (follow-up), while the G2 and G3 showed a tendency to increase the IDATE-state score.

An ANOVA was applied only at the first moment for the Dela Coleta instrument ${ }^{(16)}$, normality was verified by the Kolmogorov-Smirnov test $(p=0.245)$ and Levene test, indicating homogeneity in the means be- 
fore the treatment for self-esteem in the three groups $(p=0.226)$. The ANOVA applied for the obtained scores at the five moments previously described did not meet the sphericity assumption (Mauchlys test $p=0.000$ ), therefore, for the hypothesis test it was used the Greenhouse-Geisser correction, that indicated no difference between groups along the treatment $(p=0.437)$. Figure 2 demonstrates the distribution of groups mean scores in five assessment moments for self-esteem through the Dela Coleta instrument ${ }^{(16)}$. It was observed a self-esteem score reduction in the three groups at the beginning of the intervention and after started to increase and this tendency was sustained for the G1 and $\mathrm{G} 3$ groups. It is important to note that the $\mathrm{G} 1$ curve keeps increasing, while the G3 has a tendency to stabilize. The $\mathrm{G} 2$ curve indicates a possible decay behavior. Figure 2 demonstrates the G2 (placebo) with a different behavior from the other two groups at the second moment of assessment, for this reason, it was applied a second ANOVA which indicated no difference between the three groups $(p=0.141)$. It was noted no difference for the three groups at the end of treatment $(p=0.705)$.

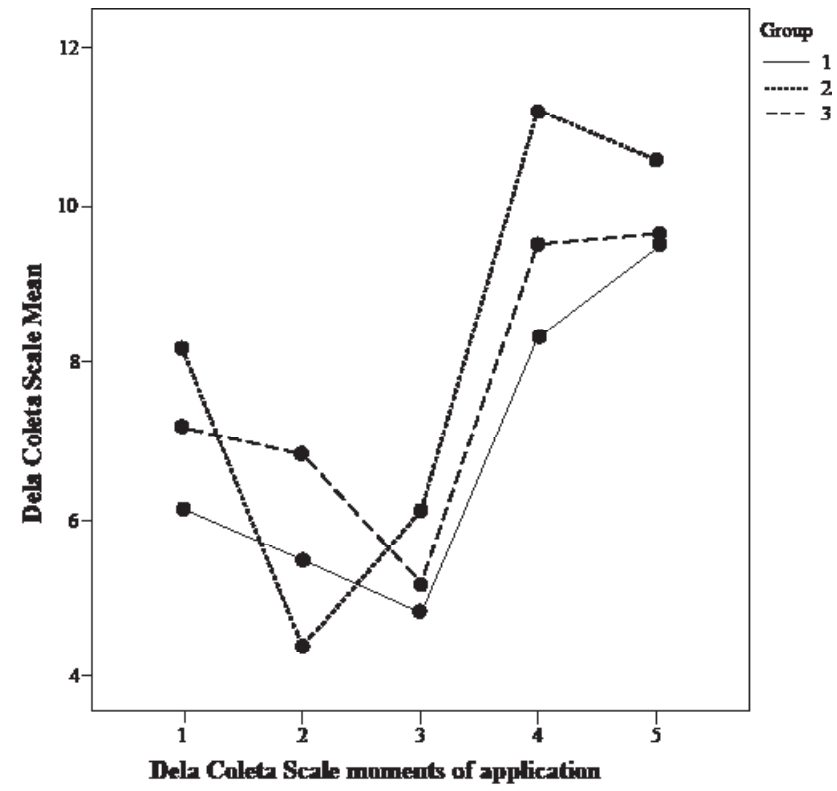

Figure 2 - Mean distribution of self-esteem scores in accordance with groups at the five moments of Dela Coleta instrument application - São Paulo, 2014.

For the variable mean blood pressure (MBP) assessed at five moments with the described instruments as mentioned before, an ANOVA was applied and the sphericity assumption was not met (Mauchlys test $p=0.000$ ), and a Greenhouse-Geisser correction was applied for hypothesis test indicating no difference between groups along the treatment $(p=0.398)$. Figure 3 demonstrates the MBP means distribution in the groups along treatment.

Lastly, for the axillary temperature measured at the five moments, an ANOVA was applied and the sphericity assumption was not met (Mauchlys test $p=0.030$ ), and a Greenhouse-Geisser correction was applied for the hypothesis test indicating no difference between groups along treatment $(p=0.875)$. Figure 4 shows the axillary temperature mean distribution in the five groups for all assessment moments.

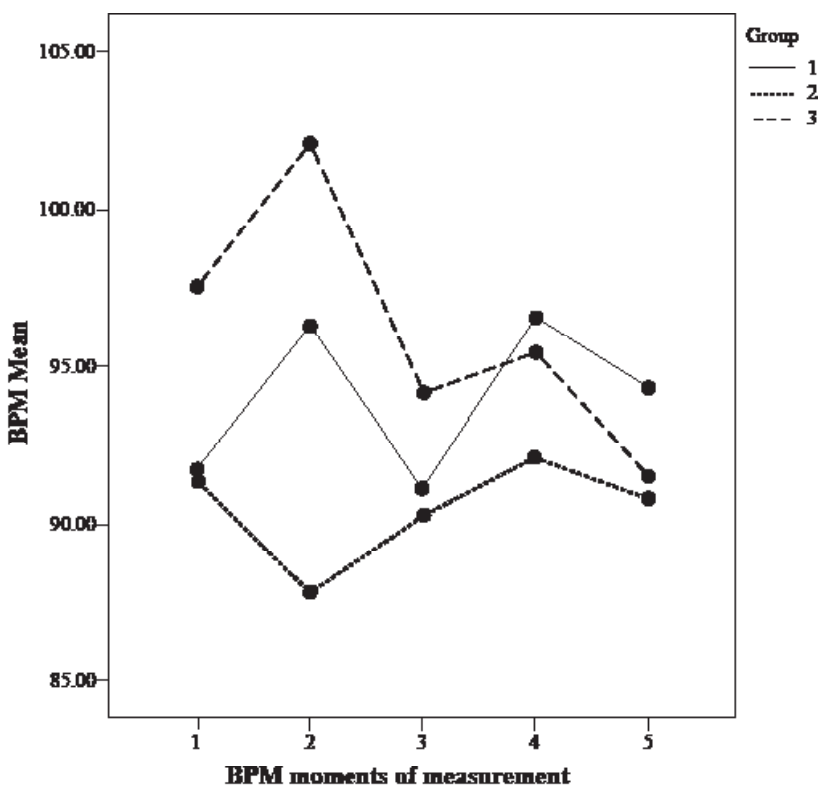

Figure 3 - Mean distribution of MBP in accordance with groups at the five moments of assessment - São Paulo, 2014.

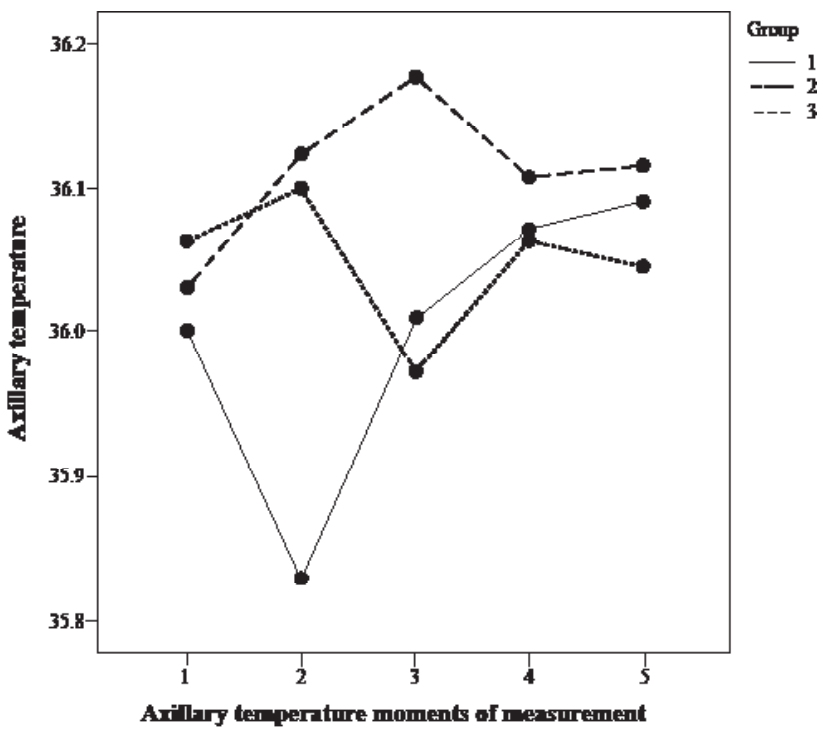

Figura 4 - Mean distribution of axillary temperature in accordance with groups at the five moments of assessment - São Paulo, 2014.

\section{DISCUSSION}

Nowadays, nursing professionals are unsatisfied with their work and it shows how much it affects their activity results. In this profession, it is needed more than the technical knowledge; there is the ability to recognize others needs and to deal with human relationships. Consider- 
ing those conditions, it becomes a necessity to care about Nursing because the physical and emotional state of those professionals interfere in reaching optimal performance or frustration ${ }^{(8)}$. Aromatherapy as other CTs tries to enhance ones physical, mental and emotional well-being ${ }^{(7)}$. The ylang ylang EO was chosen for this study due to its indication for anxiety, frustration, nervous tension, fears and depression $^{(1-2,12)}$, and assistance to reduce blood pressure ${ }^{(3)}$.

From the 45 participants who began the protocol, only 34 concluded the research. The sample loss rate was around $24 \%$ although it was still inferior to the $1 / 3$ of the expected loses for studies that uses the subjects' adherence to the treatment as intervention ${ }^{(20)}$. This is the reality not only faced by the $\mathrm{CT}$ but also by allopatic treatments, once the intervention proposal depends on the subject, similar to a prescribed treatment. Therefore, the no adherence to the treatment was an existing possibility as a result in this research because there was no therapist to do the procedure, which contributed to eliminate the possibility of a therapeutic bond interfering in the results, which is an adopted technique in studies similar to aromatherapy for anxiety ${ }^{(18)}$. Thus, the minimization of bias through the entrance tests was a strategy, excluding the subjects that did not adhere to intervention at the first week of placebo use or that did not accepted the ylang ylang odor. It was observed only one dropout in this period and all other dropouts (11) were during the first month of intervention. This situation was a study limitation suggesting a longer period for entrance tests in future trials avoiding loses in the sample, or a next clinical trial with a shorter period of time using, for example, an experimental model that induces anxiety, to avoid self-intervention and the dependence of the study to be carried out by participants. Besides that, submitting subjects to an anxiety will allow measurements in a well delimited state before and after intervention, in similarity to other studies that investigated aromatherapy for anxiety ${ }^{(19,21)}$, and one of them also applied the Anxiety Inventory as instrument ${ }^{(19)}$.

For the IDATE instrument internal consistency evaluation by the statistical indicator Cronbach Alpha $(\alpha)$ the values were 0.808 for the IDATE- trace, 0.931 for the IDATE- initial state, affirming that the instrument was considered valid and reliable with $\alpha>0.700$ values. Those findings corroborate with the instruments assessment of a similar study ${ }^{(18)}$.

The pre and post intragroup analysis demonstrated significant difference only to self-esteem in three groups, and applied the intergroup analysis; the differences were not significant as the three interventions enhanced self-esteem in similar levels. The study contributes to raise the importance of a negative control inclusion for aromatherapy. It is proposed the inhalation or to use products that uses distillated water instead of EO in its composition. That would facilitate the intergroup comparison, in cases where the EO or essence use has significant results, as the present study results.
Although the alterations in scores were not significant between groups, did the subjects notice difference in its state of anxiety and self-esteem? This question could be answered if a validated instrument that assesses emotional alterations by sensations and self-perceived behavioral changes, aiming to capture the subjects' perceptions during the intervention. Does the EO cutaneous contact produces better aromatherapeutic effects for anxiety and self-esteem than inhalation only? In this case, only studies comparing two groups of intervention as this could help in this observation. As there is no standards about the essential oils adequate dosages for aromatherapy in the literature, maybe higher concentrations of EO responds faster in comparison with an emotional nuance.

As described in the literature that the ylang-ylang EO can cause a hypotension effect or temperature alteration ${ }^{(3)}$, blood pressure and temperature was verified to detect possible alterations for the data collection instruments fulfillment. Regarding the MBP assessment along the study, it was observed that the freshener group (G3) presented an initial MBP superior to the recommended (above $95 \mathrm{mmHg}^{(22)}$ ) and after three months of intervention there was a reduction tendency that was kept during the follow up, and the G1 and $\mathrm{G} 2$ did not present the same behavior. Maybe the higher levels of EO concentration or the pure use in the freshener presents a faster answer in comparison to physiological parameters, for example, when used a $20 \%$ ylang ylang concentration during a massage, resulting in lower blood pressure after 20 minutes of intervention ${ }^{(3)}$. Regarding the temperature, there was not any significant changes observed with OE or essence, in similarity with other study ${ }^{(3)}$.

This pilot study contributes to help professionals to elaborate a more robust study design to verify if an aromatherapy done with ylang ylang oil or other EO alters the perception of anxiety and self-esteem. This study will be developed in a second phase and will use the present sample for an adequate sample size calculation. It will include a potential anxiogenic situation that will allow verifying the EO aromatherapeutic effect before and after intervention. Besides the IDATE ${ }^{(15)}$ and the Dela Coleta Scale ${ }^{(16)}$ used in the present and previous studies ${ }^{(7,18-19)}$, the association of another validated scale as the Visual Analog Humor Scale ${ }^{(23)}$, will allow assessment of possible emotional alterations by sensations and self-perceived behavioral changes ${ }^{(19)}$.

Besides the previously cited limitations, a bias in the study was also considered: the EO dosage definition, the adequate way to apply the oil and the exposition frequency to $i^{(7,18)}$. Although it is not possible to affirm the better way to use aromatherapy, more studies are needed and its methodological designs should include at least two ways to apply EO with the aim to compare its efficacy. It is raised that the ylang ylang dosage, application and frequency could be insufficient, contributing to its lack of success. Thus, it is relevant that all variables in aromatherapy studies to be explicit, because only then it will be possible to build a robust scientific literature for a correct and safe use of EO. 


\section{CONCLUSION}

It was verified that the ylang ylang essential oil significantly altered the self-esteem perception only for the three groups and the physiological parameters measured by mean blood pressure and temperature did not suffered significant changes.

This pilot study contributes to new aromatherapy investigations with the ylang ylang oil and other essential oils in the anxiety and self-esteem perception that can use as

\section{REFERENCES}

1. Rose J. O livro da aromaterapia: aplicações e inalações. Rio de Janeiro: Campus; 1995.

2. Tisserand R. A arte da aromaterapia. 13a ed. São Paulo: Roca; 1993.

3. Hongratanaworakit T, Buchbauer G. Relaxing effect o ylang ylang oil on humans after transdermal absorption. Phytother Res. 2006;20(9):758-63.

4. Imanishi J, Kuriyama H, Shigemori I, Watanabe S, Aihara $\mathrm{Y}$, Kita $\mathrm{M}$, et al. Anxiolytic effect of aromatherapy massage in patients with breast cancer. Evid Based Complement Alternat Med. 2009;6(1):123-8.

5. Cooke M, Holzhauser K, Jones M, Davis C, Finukane J. The effect of aromatherapy massage with music on the stress and anxiety levels of emergency nurses: comparison between summer and winter. J Clin Nurs. 2007;16(9):1695-703.

6. Rho KH, Han SH, Kim KS, Lee MS. Effects of aromatherapy massage on anxiety and self-esteem in Korean elderly women: a pilot study. Intern J Neurosc. 2006;116(12):1447-55.

7. Gnatta JR, Zotelli MFM, Carmo DRB, Lopes CLBC, Rogenski NM, Silva MJP. The use of aromatherapy to improve self-esteem. Rev Esc Enferm USP [Internet]. 2011 [cited 2013 Oct 26];45(5):1113-20. Available from: http://www.scielo.br/pdf/ reeusp/v45n5/en_v45n5a12.pdf

8. Vitória Regis LFL, Porto IS. A equipe de enfermagem e Maslow: (in)satisfações no_trabalho. Rev Bras Enferm [Internet]. 2006 [citado 2013 out. 26];59(4):565-8. Disponível em: http://www.scielo.br/pdf/reben/v59n4/a18v59n4.pdf

9. São Paulo (Cidade). Lei 13.717, de 08 de Janeiro de 2004. Dispõe sobre a implantação das Terapias Naturais na Secretaria Municipal de Saúde [Internet]. São Paulo; 2004 [citado 2011 set. 12]. Disponível em: http://www3.prefeitura.sp.gov. $\mathrm{br} / \mathrm{cadlem} / \mathrm{secretarias/negocios}$ juridicos/cadlem/integra. asp?alt=09012004L\%20137170000 resource the data obtained in this trial, aiming to elaborate a more robust trial, associating an anxiety inducted experimental model to reduce the intervention time and to standardize a anxiogenic situation, for example. Besides that, minimizing possible sample loses and contributing to increase the results accuracy, besides modifying the essential oil dosage, to include a negative control for the aroma and an instrument to assess behavioral states. However, it is important to note that aromatherapy presents many unknown variables that include not only the treatment application but also the treatments' frequency and duration.

10. World Health Organization. Traditional medicine: definitions [Internet]. Geneva; 2004 [cited 2013 Oct 26]. Available from: http://www.who.int/medicines/areas/traditional/ definitions/en//

11. Conselho Federal de Enfermagem (COFEN). Resolução COFEN-197/97. Estabelece e reconhece as terapias alternativas como especialidade e/ou qualificação do profissional de enfermagem [Internet]. Brasília; 1997. [citado 2013 out. 26]. Disponível em: http://novo.portalcofen.gov.br/ resoluo-cofen-1971997_4253.html

12. Lavabre M. Aromaterapia: a cura pelos óleos essenciais. Rio de Janeiro: Nova Era; 2001.

13. Andrade LHS, Gorenstein C. Aspectos gerais das escalas de avaliação de ansiedade. Rev Psiq Clín. 1998;25(6);285-90.

14. Braden N. Autoestima: como aprender a gostar de si mesmo. São Paulo: Saraiva; 1996.

15. Spielberger CD, Gorusch RL, Lushene RE. Manual for the state-trait anxiety inventory. Palo Alto: Consulting Psychologist; 1970.

16. Dela Coleta JA, Dela Coleta MF. Escalas para medida de atividade e outras variáveis psicossociais. Ribeirão Preto: EERP; 1996.

17. Corazza S. Aromacologia: uma ciência de muitos cheiros. São Paulo: SENAC; 2002.

18. Gnatta JR, Dornellas EV, Silva MJP. The use of aromatherapy in alleviating anxiety. Acta Paul Enferm [Internet]. 2011 Oct [cited 2013 Oct 26]; 24(2):257-63. Available from: http:// www.scielo.br/pdf/ape/v24n2/en_16.pdf

19. Goes TC, Antunes FD, Alves PB, Teixeira-Silva F. Effect of sweet orange aroma on experimental anxiety in humans. J Altern Complement Med. 2012;18(8):798-804. 
20. Valle EA, Viegas EC, Castro CAC, Toledo Júnior AC. A adesão ao tratamento. Rev Bras Clín Ter. 2000;26(3):83-6.

21. Faturi CB, Leite JR, Alves PB, Canton AC, Teixeira-Silva F. Anxiolytic-like effect of sweet orange aroma in Wistar rats. Prog Neuropsychopharmacol Biol Psychiatry. 2010;34(4):605-9.
22. Sociedade Brasileira de Cardiologia; Sociedade Brasileira de Hipertensão; Sociedade Brasileira de Nefrologia. V Diretrizes Brasileiras de Hipertensão Arterial [Internet]. 2006 [citado 2013 out. 26]. Disponível em: http://bvsms.saude.gov.br/ bvs/publicacoes/v_diretrizes_brasileira_hipertensao_arterial_2006.pdf

23. Zuardi AW, Karniol IG. Transcultural study of a self-rating scale for subjective states. J Bras Psiquiatr. 1981;30(5):403-6. 